\title{
Oxidation Analyses of Massive Air Ingress Accident of HTR-PM
}

\author{
Wei Xu, ${ }^{1,2,3}$ Yanhua Zheng, ${ }^{1,2,3}$ Lei Shi, ${ }^{1,2,3}$ and Peng Liu ${ }^{1,2,3}$ \\ ${ }^{1}$ Institute of Nuclear and New Energy Technology, Tsinghua University, Beijing 100084, China \\ ${ }^{2}$ Collaborative Innovation Center of Advanced Nuclear Energy Technology, Beijing 100084, China \\ ${ }^{3}$ Key Laboratory of Advanced Reactor Engineering and Safety, Ministry of Education, Beijing 100084, China
}

Correspondence should be addressed to Lei Shi; shlinet@tsinghua.edu.cn

Received 12 April 2016; Revised 20 June 2016; Accepted 22 June 2016

Academic Editor: Eugenijus Ušpuras

Copyright (C) 2016 Wei Xu et al. This is an open access article distributed under the Creative Commons Attribution License, which permits unrestricted use, distribution, and reproduction in any medium, provided the original work is properly cited.

\begin{abstract}
The double-ended guillotine break (DEGB) of the horizontal coaxial gas duct accident is a serious air ingress accident of the high temperature gas-cooled reactor pebble-bed module (HTR-PM). Because the graphite is widely used as the structure material and the fuel element matrix of HTR-PM, the oxidation analyses of this severe air ingress accident have got enough attention in the safety analyses of the HTR-PM. The DEGB of the horizontal coaxial gas duct accident is calculated by using the TINTE code in this paper. The results show that the maximum local oxidation of the matrix graphite of spherical fuel elements in the core will firstly reach $3.75 * 10^{4} \mathrm{~mol} / \mathrm{m}^{3}$ at about $120 \mathrm{~h}$, which means that only the outer $5 \mathrm{~mm}$ fuel-free zone of matrix graphite will be oxidized out. Even at $150 \mathrm{~h}$, the maximum local weight loss ratio of the nuclear grade graphite in the bottom reflectors is only 0.26 . Besides, there is enough time to carry out some countermeasures to stop the air ingress during several days. Therefore, the nuclear grade graphite of the bottom reflectors will not be fractured in the DEGB of the horizontal coaxial gas duct accident and the integrity of the HTR-PM can be guaranteed.
\end{abstract}

\section{Introduction}

The high temperature gas-cooled reactor has been considered as a candidate of the generation IV nuclear energy system technologies because of its advanced inherent safety properties [1]. The most important property is that the fuel element temperature will never exceed the design limitation during any accident, even in the case of failure of all active cooling systems and complete loss of coolant [2]. At the end of 2012, based on the successful design and operation of the $10 \mathrm{MW}$ high temperature gas-cooled test reactor (HTR-10), the 200 MWe high temperature gas-cooled reactor pebblebed module (HTR-PM), designed by the Institute of Nuclear and New Energy Technology (INET) of Tsinghua University, was started to be constructed in Rongcheng, Shandong Province of China. Figure 1 shows the cross section of the primary circuit of the HTR-PM [1].

As illustrated in Figure 1, the primary circuit pressure boundary of the HTR-PM is constituted by the reactor pressure vessel, the steam generator pressure vessel, and the horizontal coaxial gas duct vessel. The break and leak of the primary circuit pressure boundary may lead to air ingress accident, which have got enough attention in the safety analyses of the HTR-PM. In the accident analyses of the HTR-PM, despite the rare probability, the beyond design basic accidents (BDBA) still got a lot of concerns because of the possible severe consequences. In the air ingress accident analyses of HTR-PM, there are two kinds of air ingress accidents which are regarded as BDBA: one is the doubleended guillotine break (DEGB) of the horizontal coaxial gas duct which could result in large amount of air ingress into the primary circuit; the other is the simultaneous rupture of both upper and lower fuel discharging pipes connected to the primary loop which could also cause large amount of air ingress due to the chimney effect [3].

Because of the large cross-sectional area and having no isolation valve on the horizontal coaxial gas duct, the DEGB of the horizontal coaxial gas duct is a severe kind of air ingress accident and it is considered as an extremely hypothetical accident of HTR-PM. When the DEGB of the horizontal coaxial gas duct accident happens, as discussed by Liu [4], the following progress can be divided into three stages: (1) 


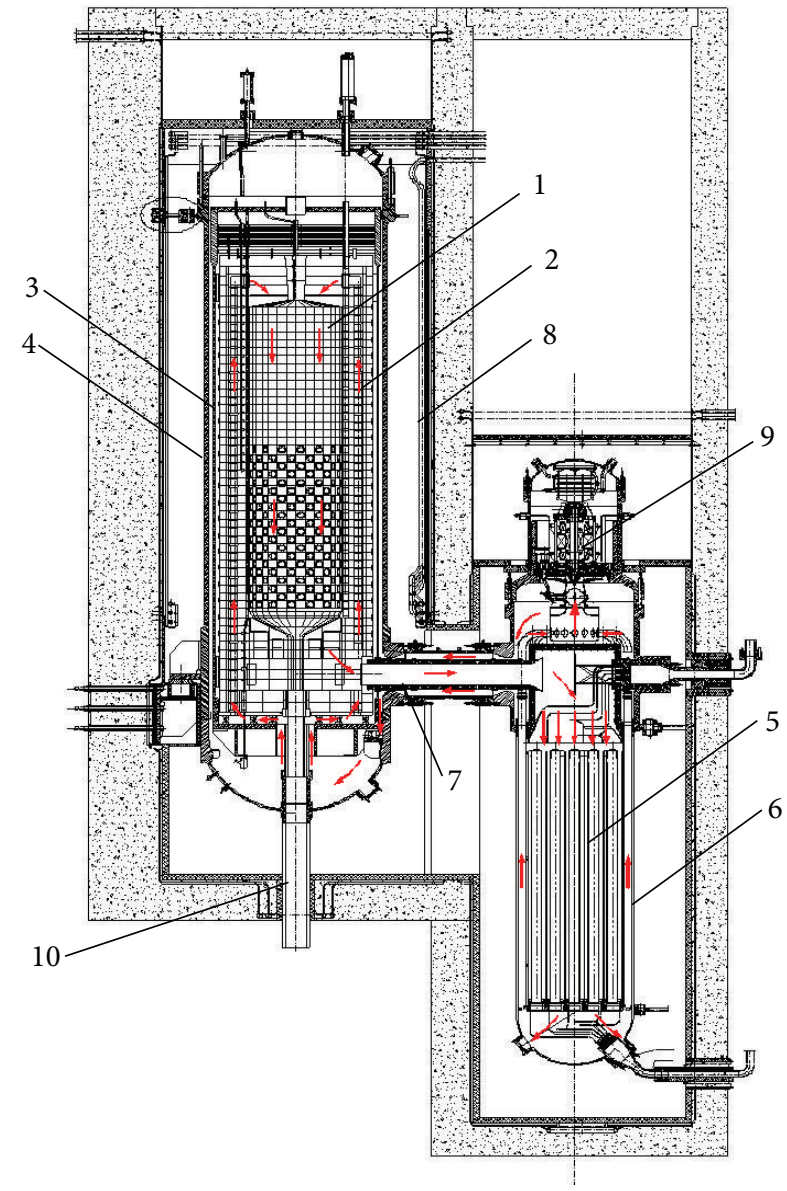

FIgure 1: Cross section of the primary circuit of the HTR-PM. (1) Reactor core; (2) side reflector and carbon thermal shield; (3) core barrel; (4) reactor pressure vessel; (5) steam generator; (6) steam generator vessel; (7) coaxial gas duct; (8) water-cooling panel; (9) blower; (10) fuel discharging tube.

the helium quickly bursts into the rector cavity due to the large pressure difference between the primary circuit and the reactor cavity; (2) after depressurization, stable natural circulation will be built because of the gas density difference between the hot leg and the cold leg; (3) after the stable natural circulation is built up, the graphite in the reactor will be oxidized by air during a long period.

When the stable natural circulation is built up, air diffuses into the reactor from the inner coaxial gas duct and then flows from the bottom reflector, passing away the core, to the top reflector. Then the air flows from the cold helium plenum, passing through the circular channel, to the cavity between the reactor pressure vessel and the core vessel. Finally the air flows from the outer coaxial gas duct to the reactor cavity.

As discussed by Zhou et al. [5], nuclear grade graphite is widely used as matrix of the spherical fuel elements, the reflectors, and structure material of the HTR-PM. During the air ingress accident, the graphite would react with oxygen in the air. Oxidation of matrix graphite may increase the release of the radioactivity in the spherical fuel elements, while the oxidation of bottom reflector may decrease the mechanical strength which could influence the structure integrity of the reactor. So the oxidation analyses are very important in the air ingress accident analyses of the HTR-PM.

The mechanism of graphite oxidation is very complex. As discussed by some researchers $[6,7]$, the reaction mechanism can be divided into three parts according to the temperature. Figure 2 shows the schematic of oxidation of porous carbon materials by gaseous oxidants [6].

As shown in Figure 2, zone I is called the chemical regime (CR), where the reaction temperature is low and the reaction rate is very small. In this regime, the oxidation reaction rate is dominated by the chemical reaction kinetics and the oxygen can penetrate into the whole graphite. Zone II is called the inpore diffusion controlled regime (IPDR), where the temperature is medium and the oxidation rate is dominated by both chemical reaction kinetics and diffusion mechanism. The oxygen concentration profile is much steeper than that in CR. Zone III is called the mass transfer controlled regime (BLDR), where the reaction temperature is high and the oxidation rate is dominated by the boundary diffusion mechanism. In this regime, the oxidation rate is much larger than that in CR and IPDR. The oxygen is nearly only distributed on the surface of the graphite. The penetration depth is very small. The influence of oxidation controlled by different regime on the mechanical strength is different. When the graphite oxidation happened in CR or IPDR, the mechanical strength decreases due to the decrease of the nuclear graphite density. However, when the graphite oxidation happened in BLDR, the oxidation causes low strength loss because the graphite density nearly does not change in this regime.

This paper calculated the DEGB of the horizontal coaxial gas duct accident by TIme Dependent Neutronics and TEmperatures (TINTE) code which is developed by the Juelich Research Center of Germany. Based on the calculation results, this paper mainly analyzed the oxidation of the matrix graphite of spherical fuel elements and the bottom reflector and further discussed the influence of bottom reflector oxidation on the integrity analyses in the DEGB of the horizontal coaxial gas duct accident.

\section{Oxidation Model of TINTE Code}

The DEGB of the horizontal coaxial gas duct accident was calculated by TINTE code in this paper. The system program TINTE code can simulate the reactor physics and the thermal hydraulics dynamic behavior of the primary circuit of high temperature gas-cooled reactors which has been discussed by some researchers [8-10]. The overall simulation of the multiconnected system is achieved by iteration in TINTE. The reliability of TINTE code has been validated by a series of experiments [10-12]. The chemical part of TINTE is programmed based on the VELUNA corrosion experiments [12]. In addition, for further research of the oxidation behavior of nuclear graphite, the NACOK facility has been built at Juelich Research Center. As discussed by Zheng and Stempniewicz [13], a detailed oxidation model has been applied in TINTE according to the experiment results on NACOK facility. 


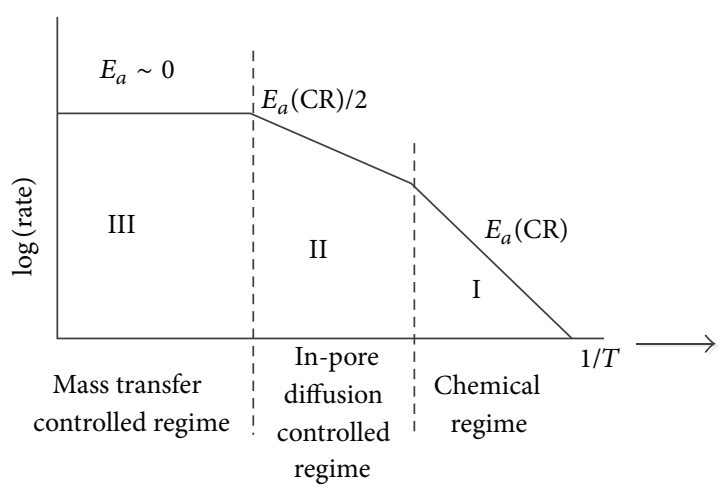

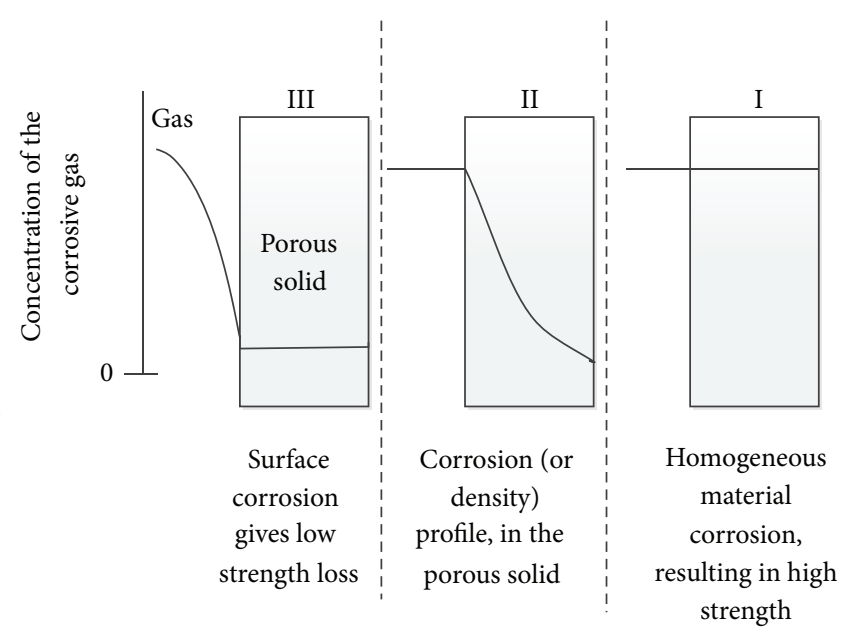

FIGURE 2: The schematic of oxidation of porous carbon materials by gaseous oxidants.

TINTE code considered three reactions in the air ingress accident, as shown in (1) (3). Reaction (2) is the endothermic reaction, while reactions (1) and (3) are the exothermic reactions. The total chemical reaction heat is determined by all of these three reactions and the amount of the graphite oxidation can be calculated by applying reaction (2) and reaction (3):

$$
\begin{gathered}
2 \mathrm{CO}+\mathrm{O}_{2} \longrightarrow 2 \mathrm{CO}_{2} \quad \Delta H_{1}=-5.64 \times 10^{5} \mathrm{~J} / \mathrm{mol} \\
\mathrm{CO}_{2}+\mathrm{C} \rightleftarrows 2 \mathrm{CO} \quad \Delta H_{2}=1.71 \times 10^{5} \mathrm{~J} / \mathrm{mol} \\
\mathrm{O}_{2}+\mathrm{C} \longrightarrow \mathrm{CO}_{2} \quad \Delta H_{3}=-3.94 \times 10^{5} \mathrm{~J} / \mathrm{mol}
\end{gathered}
$$

The reaction rates of reactions (1) (3) are shown, respectively, as

$$
\begin{aligned}
& F_{1}=1.3 \times 10^{20} * \exp \left(-\frac{1.44 \times 10^{5}}{R * T_{G}}\right) * C(\mathrm{CO}) * \sqrt{C\left(\mathrm{O}_{2}\right)} * \sqrt{C\left(\mathrm{H}_{2} \mathrm{O}\right)}, \\
& F_{2}=\frac{2.2 \times 10^{8} * \exp \left(-\left(3.58 \times 10^{4}\right) / T_{W}\right) * \mathrm{CGR} * 0.012 *(1-b)^{2 / 3} * C_{W}\left(\mathrm{CO}_{2}\right)}{1+8.1 \times 10^{-6} * \exp \left(\left(1.7 \times 10^{4}\right) / T_{W}\right) * \sqrt{C(\mathrm{CO})}+179 * \exp \left(-\left(9.82 \times 10^{3}\right) / T_{W}\right) * C_{W}\left(\mathrm{CO}_{2}\right)}, \\
& F_{3}=7.2 \times 10^{9} * 2.3148 \times 10^{-9} * \exp \left(-\frac{1.614 \times 10^{4}}{T_{W}}\right) *\left(R * T_{G}\right) * F_{V} *(1-b)^{2 / 3} * C_{W}\left(\mathrm{O}_{2}\right) .
\end{aligned}
$$

In (4) (6), $F_{1}, F_{2}$, and $F_{3}$ are, respectively, the reaction rates of reactions (1), (2), and (3), $\mathrm{mol} /\left(\mathrm{m}^{3} \cdot \mathrm{s}\right) . C(i)$ is the concentration of gas $i$ in the boundary layer of solid wall, $\mathrm{mol} / \mathrm{m}^{3} ; C_{W}(i)$ is the concentration of gas $i$ on the solid wall, $\mathrm{mol} / \mathrm{m}^{3}$, while $i$ means the gas species, $\mathrm{O}_{2}, \mathrm{CO}, \mathrm{CO}_{2}$, and $\mathrm{H}_{2} \mathrm{O}$. CGR is the density of nuclear graphite, $\mathrm{mol} / \mathrm{m}^{3}$. $F_{V}$ means the area density of spherical fuel element, $\mathrm{m}^{2} / \mathrm{m}^{3}$, while $b$ means the weight loss ratio of nuclear graphite. $T_{G}$ and $T_{W}$, respectively, mean the gas temperature and the solid wall temperature, $K . R$ is the ideal gas constant, which is $8.314 \mathrm{~J} /(\mathrm{mol} \cdot \mathrm{K})$.

Based on (4) (6) and the mechanism of graphite oxidation, it is known that the graphite oxidation rate is mainly determined by the oxidant gas concentration on the solid surface and the solid temperature in the primary circuit. The oxidant gas concentration on the solid surface is determined by the concentration in the main flow and the mass transfer velocity in the boundary layer. Due to the principle of mass conservation, the gas concentration balance equations in the boundary layer are shown as follows:

$$
\begin{aligned}
& \text { beta }\left(\mathrm{O}_{2}\right) \times\left(C\left(\mathrm{O}_{2}\right)-C_{W}\left(\mathrm{O}_{2}\right)\right)=F_{3}, \\
& \text { beta }(\mathrm{CO}) \times\left(C(\mathrm{CO})-C_{W}(\mathrm{CO})\right)=-2 \cdot F_{2}, \\
& \text { beta }\left(\mathrm{CO}_{2}\right) \times\left(C\left(\mathrm{CO}_{2}\right)-C_{W}\left(\mathrm{CO}_{2}\right)\right)=F_{2}-F_{3}, \\
& q k(I)=- \text { gama }(I) \times C_{f}(I), \\
& \text { gama }\left(\mathrm{O}_{2}\right) \cdot C\left(\mathrm{O}_{2}\right)+q k\left(\mathrm{O}_{2}\right)+\operatorname{beta}\left(\mathrm{O}_{2}\right) \\
& \quad \cdot\left(C\left(\mathrm{O}_{2}\right)-C_{W}\left(\mathrm{O}_{2}\right)\right)=-F_{1}, \\
& \text { gama }(\mathrm{CO}) \cdot C(\mathrm{CO})+q k(\mathrm{CO})+\operatorname{beta}(\mathrm{CO}) \\
& \quad \cdot\left(C(\mathrm{CO})-C_{W}(\mathrm{CO})\right)=-2 \cdot F_{1}, \\
& \text { gama }\left(\mathrm{CO}_{2}\right) \cdot C\left(\mathrm{CO}_{2}\right)+q k\left(\mathrm{CO}_{2}\right)+\operatorname{beta}\left(\mathrm{CO}_{2}\right) \\
& \quad \cdot\left(C\left(\mathrm{CO}_{2}\right)-C_{W}\left(\mathrm{CO}_{2}\right)\right)=2 \cdot F_{1} .
\end{aligned}
$$


$C_{f}(i)$ is the concentration of gas $i$ in the main flow, $\mathrm{mol} / \mathrm{m}^{3}$. beta $(i)$ is the mass transfer coefficient of gas $i$ on the solid wall, $\mathrm{s}^{-1}$. gama $(i)$ is the mass transfer coefficient of gas $i$ in the boundary layer, and $\mathrm{s}^{-1} . q k(i)$ is the gas source of gas $i$ in the main flow, $\mathrm{mol} /\left(\mathrm{m}^{3} \cdot \mathrm{s}\right)$.

According to (1) (13), TINTE can calculate the concentrations, the amount of nuclear graphite oxidation, and the chemical reaction heat which will be discussed in detail in the next section.

\section{Results and Discussion}

The DEGB of the horizontal coaxial gas duct accident of HTR-PM is simulated by TINTE code. Figure 3 shows the TINTE calculation model of the HTR-PM [1].

When the natural circulation is built up in the DEGB of the horizontal coaxial gas duct accident, air diffuses into the reactor from the inner coaxial gas duct and then passes the reactor core from the bottom reflectors with an upward flow direction. The oxygen first reacts with the bottom reflectors and then reacts with the matrix graphite of spherical fuel elements in the core. So the analyses of the graphite oxidation are important for both the structure integrity and fuel element damage analyses of the HTR-PM.

According to the above demonstration and assuming that the amount of air that could diffuse into the reactor is infinite, this paper mainly discusses the graphite oxidation of the core and the bottom reflectors.

3.1. Graphite Oxidation in the Core. The diameter of the spherical fuel elements is $60 \mathrm{~mm}$ and the TRISO fuel particles dispersed in the fuel zone whose diameter is $50 \mathrm{~mm}$. There are no fuel particles in the outer $5 \mathrm{~mm}$ thick zone which is called fuel-free zone. When the air ingress accident happens, the matrix graphite is oxidized by the oxygen in air. In different location of the reactor core, the temperature of spherical fuel elements and the oxygen concentration are different. So the oxidation rate is also different. In the location where the oxidation rate is the maximum, assuming that the oxidation is homogeneous on the graphite surface, the first fuel particles will be exposed if the outer fuel-free zone of matrix graphite is completely consumed. Figure 4 shows the maximum local matrix graphite oxidation in the reactor core.

Figure 4 illustrates the maximum local matrix graphite oxidation in the reactor core. At about $120 \mathrm{~h}$, the amount of maximum local matrix graphite oxidation reaches $3.75 *$ $10^{4} \mathrm{~mol} / \mathrm{m}^{3}$ and the weight loss ratio of a spherical fuel element reaches 0.42 , which means that the outer $5 \mathrm{~mm}$ fuelfree zone of matrix graphite is completely oxidized out and the fuel particles will be exposed. As discussed by some researchers $[6,7]$, when the oxidation reaction is dominated by the boundary diffusion mechanism in BLDR, the oxygen is nearly only distributed on the surface of the graphite and the penetration depth is very small. Oxidation reaction only happens on the surface of the graphite in this regime. So the oxygen partial pressure on the graphite surface has an obvious influence on the oxidation rate. The configuration of the spherical fuel elements in the pebble bed and the gas flow direction both influence the flow field around the spherical fuel element. The oxygen partial pressure is different on the matrix graphite surface. Thus the oxidation on the graphite surface is inhomogeneous. A factor named GITO is defined to estimate this heterogeneous oxidation on the surface of the matrix graphite. According to Moormann and Hissen [14], the value of GITO is between 3 and 9. If GITO $=3$, at about $23 \mathrm{~h}$, the maximum local matrix graphite oxidation reaches $1.25 * 10^{4} \mathrm{~mol} / \mathrm{m}^{3}$ and the first fuel particle will be exposed. If $\mathrm{GITO}=6$, the time and the maximum local matrix graphite oxidation are changed to about $9 \mathrm{~h}$ and $6.25 * 10^{3} \mathrm{~mol} / \mathrm{m}^{3}$, respectively. The most severe condition is GITO $=9$. At this condition, the time and the maximum local matrix graphite oxidation are changed to about $5 \mathrm{~h}$ and $4.16 * 10^{3} \mathrm{~mol} / \mathrm{m}^{3}$, respectively.

Based on the oxidation analyses of matrix graphite in this paper, it is known that the first fuel particle will be exposed at about $120 \mathrm{~h}$ under the DEGB of the horizontal coaxial gas duct accident. It means that the exposure of fuel particles needs a relatively long time which is about 5 days. This long time is enough for people to take some protective measures. In addition, taking the heterogeneous oxidation on the surface of spherical matrix graphite into consideration, the first fuel particle will be exposed at about $5 \mathrm{~h}$ when GITO is equal to 9 which is the most severe case, but the ratio of the maximal oxidized fuel elements is very small. Even under this condition, the $\mathrm{SiC}$ layer of the fuel particle still can retain the radioactive products and some protective measures will be taken to mitigate the consequence of the air ingress accident.

3.2. Graphite Oxidation in the Bottom Reflector. As mentioned above, the oxidation in IPDR or CR of the bottom reflectors is very important for the structure integrity analyses. Many studies [15-17] have been done to research the effect of graphite oxidation on the mechanical strength of the nuclear grade graphite. The results show that the graphite mechanical strength will decrease exponentially with the weight loss ratio of graphite.

If the amount of the bottom reflector oxidation reaches a certain value, it may damage the structural integrity. As discussed in the final report of Idaho National Laboratory [15] in 2011, the average weight loss ratio for fracture of IG-110 is 0.647 based on the experiments results, while in the simulation results by MATLAB SIMULINK the average weight loss ratio for fracture of IG-110 is 0.58 which is similar to the experiments results.

The oxidation mechanism in the experiments and simulations of INL [15] are both in IPDR. Therefore, calculating the weight loss ratio of the graphite in the bottom reflectors and estimating the oxidation mechanism is very important to analyze the integrity of the bottom reflector under the DEGB of the horizontal coaxial gas duct accident.

However, in the oxidation model of TINTE, there are three reactions needing to be considered for the bottom reflector. Under the same temperature, the oxidation rate and oxidation mechanism of reaction (2) and reaction (3) are different. So it is necessary to judge which reaction has happened in the bottom reflector. In order to do so, the chemical reaction heat needs to be discussed. 


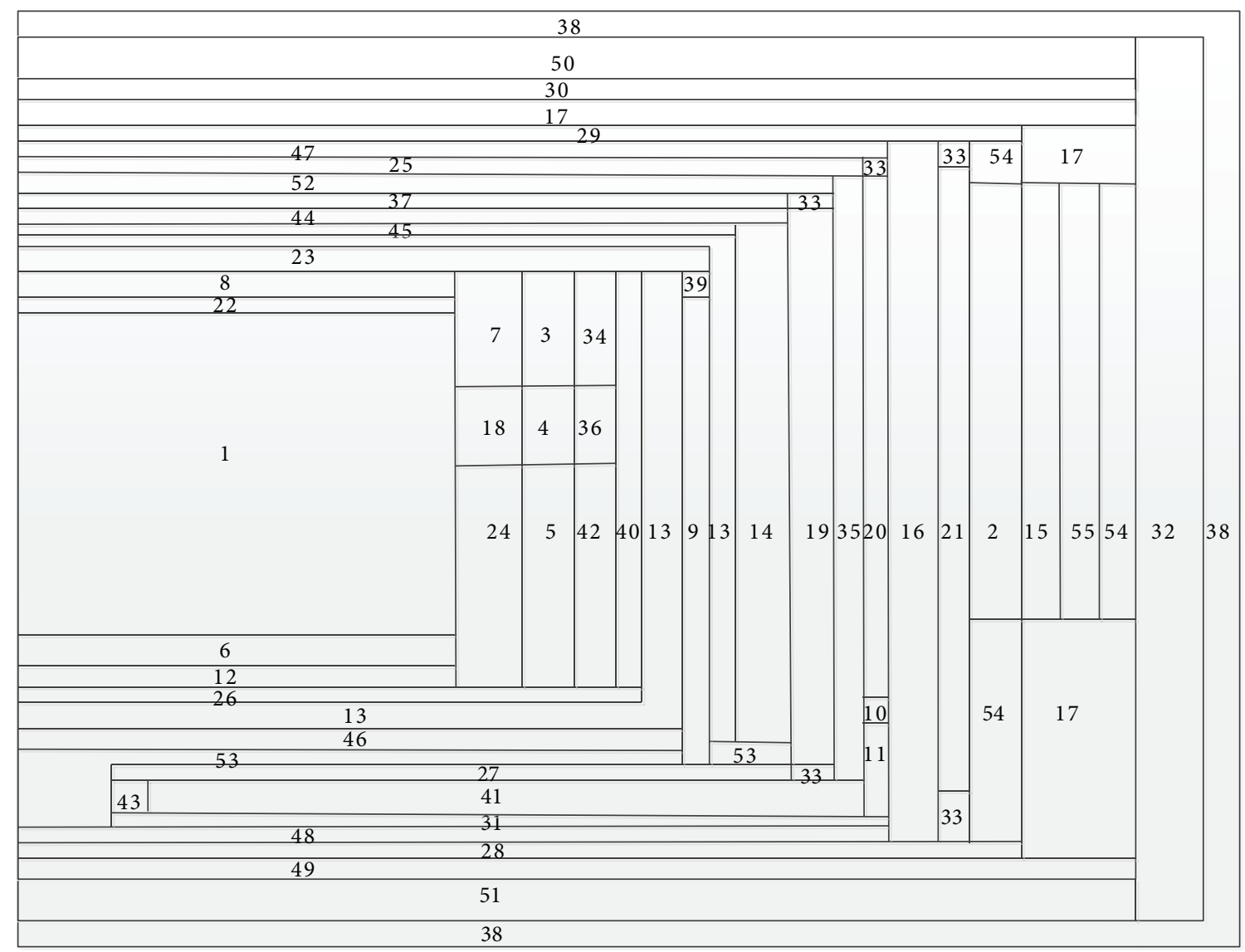

Figure 3: TINTE model of the HTR-PM. (1) Core; (2) water panel; (3-5) control rod channel; (6 and 12) bottom reflector; (7, 13, 18, 24, 34, 36 , and 42) side reflector; (8) top reflector; (9) coolant channel; (10 and 11) core inlet cavity; (14, 45, and 46) carbon brick; (15, 21, 28-30, and 54) air gap; (16, 47, and 48) reactor pressure vessel; (17 and 49) thermal insulation; (19, 20, 25, and 37) helium gap; (22) core top cavity; (23) cold helium plenum; (26) hot helium plenum; (27) core bottom cavity; (31) RPV bottom cavity; (32, 50, and 51) concrete; (35, 41, 44, 52, and 53) core barrel and metal internals; (38) air boundary; (39) throttle; (40) leakage flow; (43) flow passage; (55) metallic plate.

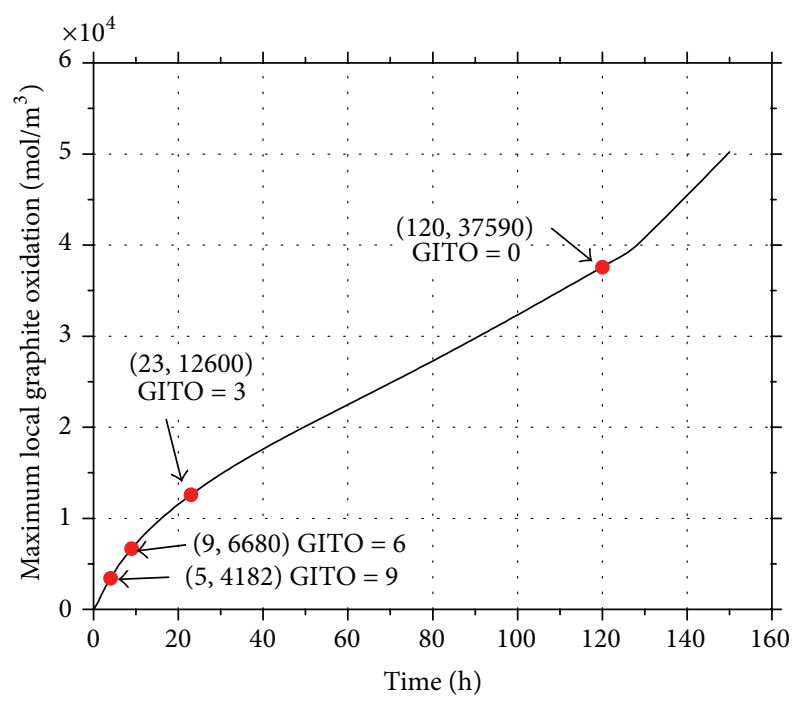

FIgURE 4: The maximum local graphite oxidation in the core.
Figure 5 demonstrates the distribution of chemical reaction heat at different time in the core and the bottom reflectors. The height of the bottom reflectors is from $Z=1120 \mathrm{~cm}$ to $Z=1226 \mathrm{~cm}$. Reaction (2) is endothermic reaction while reaction (3) is exothermic reaction. From Figure 5, it can be seen that the oxidation reaction (3) mainly occurs in the bottom reflectors. In the reactor core, the exothermic reaction (3) mainly happens at the bottom part of the core, while the endothermic reaction (2) mainly happens in the middle part. This is due to the low temperature and low concentration of oxidant gas in the upper part of the reactor core. Based on what has been demonstrated, it can be considered that reaction (3) mainly happens in the bottom reflectors. So in the following oxidation analyses of the bottom reflectors only reaction (3) needs to be considered.

From Figure 5(c), it is found that there is no oxidation reaction happening at the bottom part of the bottom reflectors. Due to the advanced inherent safety properties of HTR-PM, after the DEGB of the horizontal coaxial gas duct accident happened, the residual heat of reactor core could be removed by heat conduction, natural convection, 


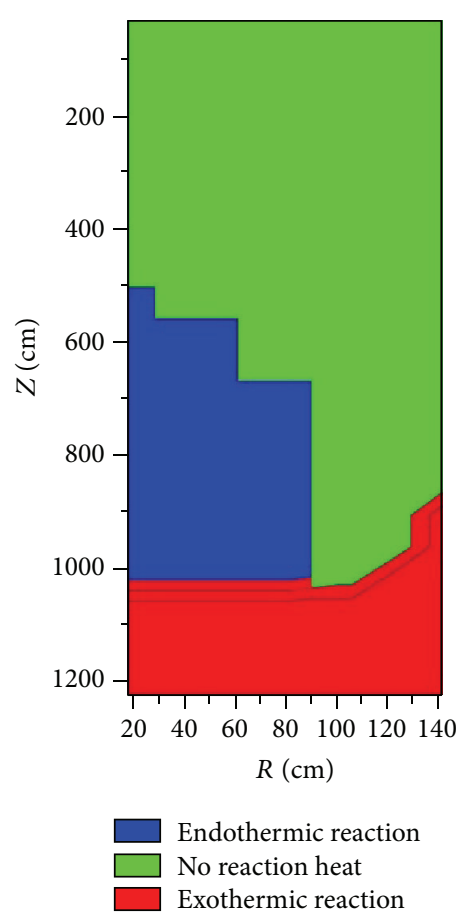

(a) $1 \mathrm{~h}$

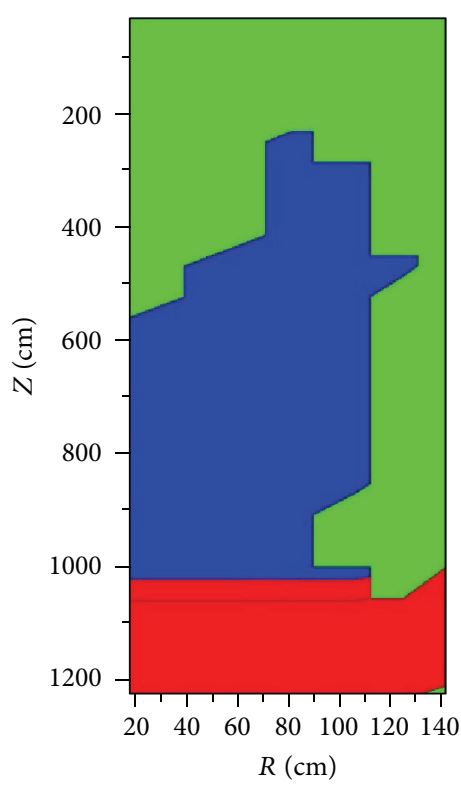

Endothermic reaction

No reaction heat

Exothermic reaction

(b) $10 \mathrm{~h}$

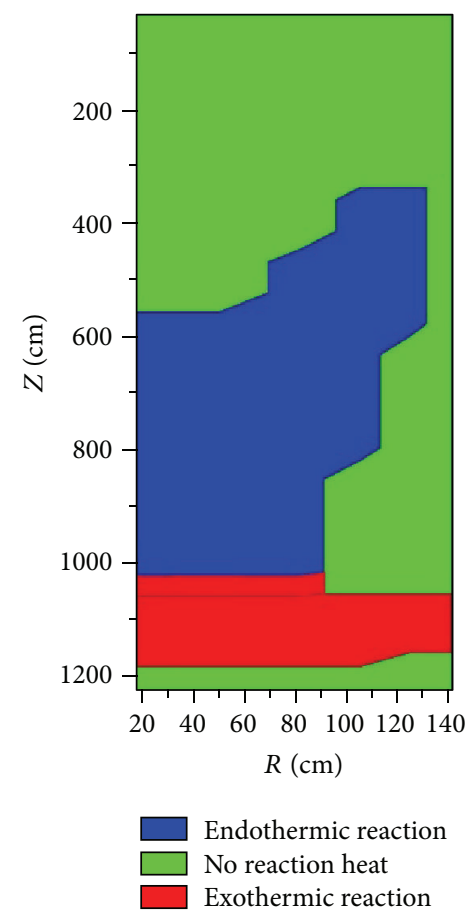

(c) $100 \mathrm{~h}$

FIGURE 5: Schematic diagram of the chemical reaction heat distribution in the reactor core and the bottom reflectors: (a) $1 \mathrm{~h}$, (b) $10 \mathrm{~h}$, and (c) $100 \mathrm{~h}$.

TABLE 1: The average temperature of locations 1, 2, and 3 within 150 hours.

\begin{tabular}{lc}
\hline Location & Average temperature $\left({ }^{\circ} \mathrm{C}\right)$ \\
\hline 1 & 678.5 \\
2 & 726.2 \\
3 & 784.9 \\
\hline
\end{tabular}

and the radiation through the pebble bed, reflectors, and pressure vessel to the water panel in the reactor cavity. The temperature of the reactor would be finally reduced by these natural physical processes. At the bottom part of the bottom reflectors, the graphite temperature is firstly reduced below $600^{\circ} \mathrm{C}$ as shown in Figure 7. The graphite oxidation rate is very small when the graphite temperature is below $600^{\circ} \mathrm{C}$. So there is nearly no oxidation reaction happening at the bottom part of the bottom reflector. Figure 6 shows the location of the maximum local graphite oxidation of the bottom reflectors.

Figure 6 depicts the location of the maximum local graphite oxidation of the bottom reflector and that it moves upward with time. The reason is that the graphite temperature of the upper part of the bottom reflectors is higher than that of the bottom part. During the first 28 hours the maximum local graphite oxidation happens in location 1 , and from $28 \mathrm{~h}$ to $89 \mathrm{~h}$ the maximum local graphite oxidation happens in location 2. After 89 hours the maximum local graphite oxidation happens in location 3 . Figure 7 shows the graphite temperature of these three locations versus time and Table 1

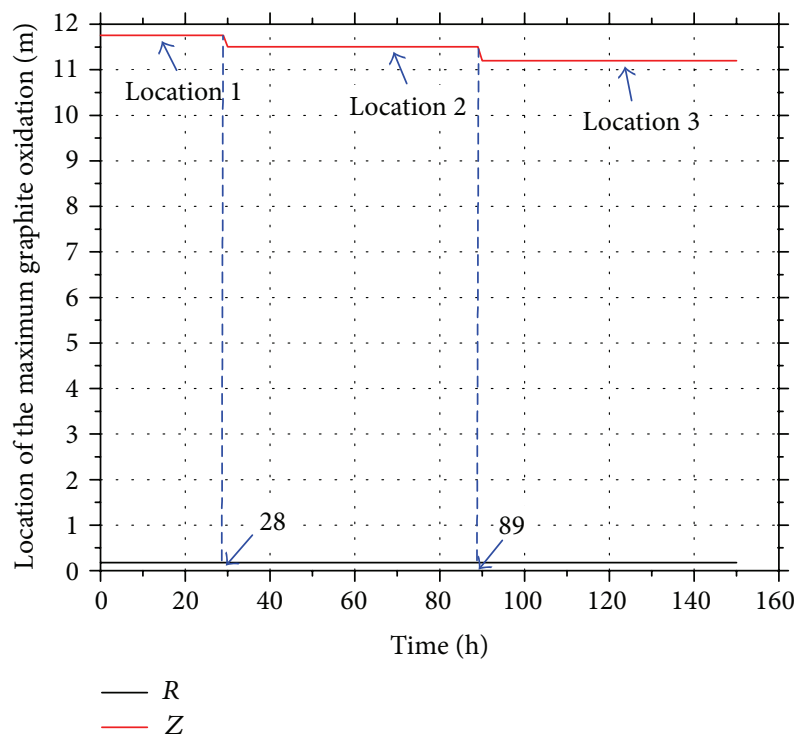

FIGURE 6: The location of the maximum local graphite oxidation of the bottom reflectors.

gives the average temperature within 150 hours of these locations.

Temperature has a very important effect on the graphite oxidation rate. The oxidation in BLDR changes the crosssectional area which load is applied on, while the oxidation in IPDR or CR changes the graphite density and affects the 


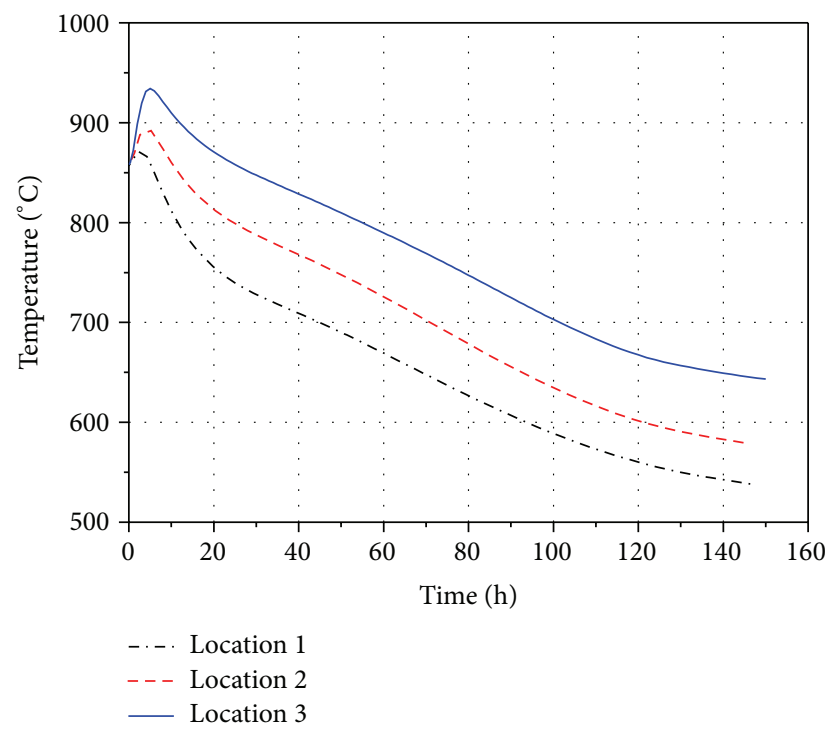

Figure 7: The temperature of locations 1, 2, and 3 versus time.

mechanical strength. In addition, the oxidation in IPDR can also change the cross-sectional area because the oxidation in this regime not only happens on the surface of the graphite but also happens in the inner part of the graphite. In the experiment of INL [15], the nuclear grade graphite is IG110 , which is the same as the bottom reflectors of HTR-PM. The oxidation in IPDR was studied in the experiments and simulations of INL [15]. Figure 8 shows the transient relative concentration profile in the nuclear grade graphite IG-110.

Based on the transient oxidation model of the previous study [18], Figure 8 shows the transient profile of oxygen concentration relative to surface in the nuclear grade graphite. It is clear that at $801^{\circ} \mathrm{C}$ and $898^{\circ} \mathrm{C}$ the oxygen could diffuse into the inner of the graphite, which means the oxidation is in IPDR at $801^{\circ} \mathrm{C}$ and $898^{\circ} \mathrm{C}$. It can be seen from Figure 7 that the temperatures of location 1 and location 2 are always smaller than $898^{\circ} \mathrm{C}$. As to location 3 , in the early 10 hours the temperature is larger than $898^{\circ} \mathrm{C}$, and, after 10 hours, the temperature is always smaller than $898^{\circ} \mathrm{C}$. Based on Table 1, the average temperatures within 150 hours of the three locations are all smaller than $801^{\circ} \mathrm{C}$. So the graphite oxidation of bottom reflectors is in IPDR which is the same with the experiments and simulations of INL [15]. Figure 9 shows the weight loss ratio of these 3 locations.

Figure 9 demonstrates that, at $150 \mathrm{~h}$, the weight loss ratios of these three locations are, respectively, about $0.159,0.22$, and 0.26 . According to the experiments results by INL [15], the average weight loss ratio for fracture of IG-110 is 0.647 , while the simulation results show this fracture weight loss ratio is 0.58 . The maximum weight loss ratio of location 3 at $150 \mathrm{~h}$ is 0.26 which is obviously smaller than the INL results of 0.647 or 0.58 . It can be concluded that the nuclear grade graphite of the bottom reflectors would not fracture and the structure damage of the reactor core would not happen in the DEGB of the horizontal coaxial gas duct accident.

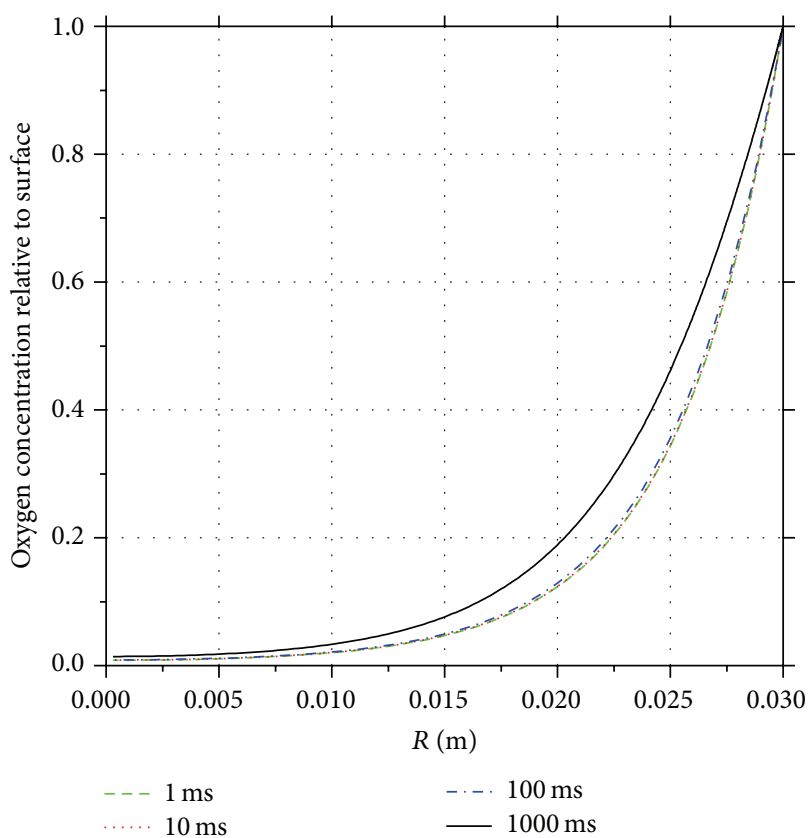

(a)

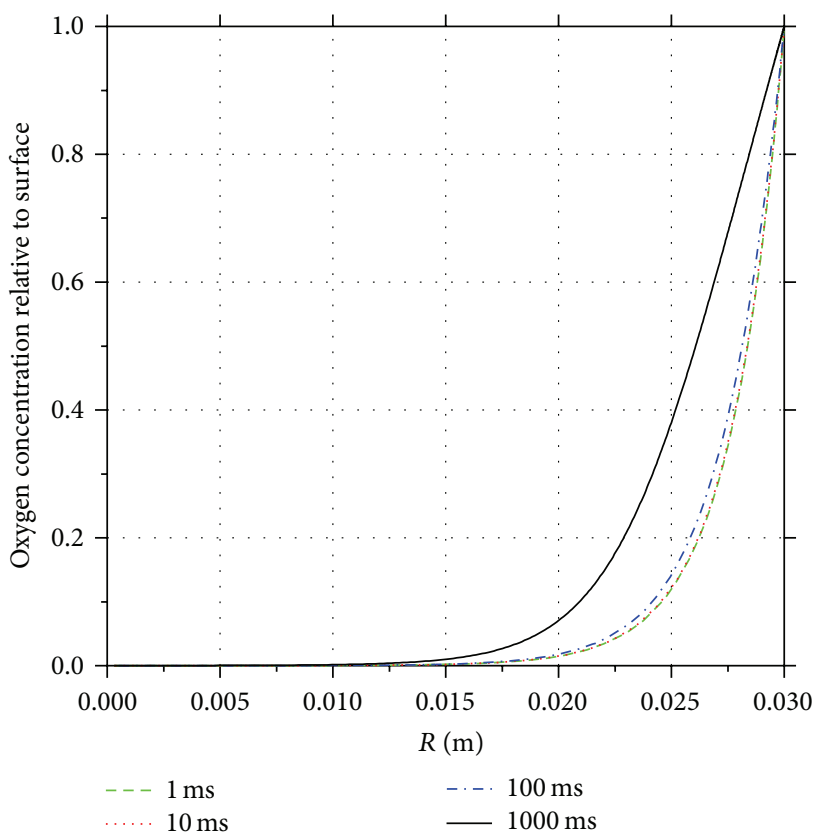

(b)

FIGURE 8: Transient profile of oxygen concentration relative to the graphite surface of IG-110.

\section{Conclusion}

The possibility of the DEGB of the horizontal coaxial gas duct is extremely rare and it is a serious air ingress accident of the HTR-PM. In order to analyze the oxidation performance of the nuclear grade graphite of the HTR-PM under this kind of air ingress accident, TINTE code has been adopted to simulate this accident. Based on the calculation results, the conclusions are the following: 


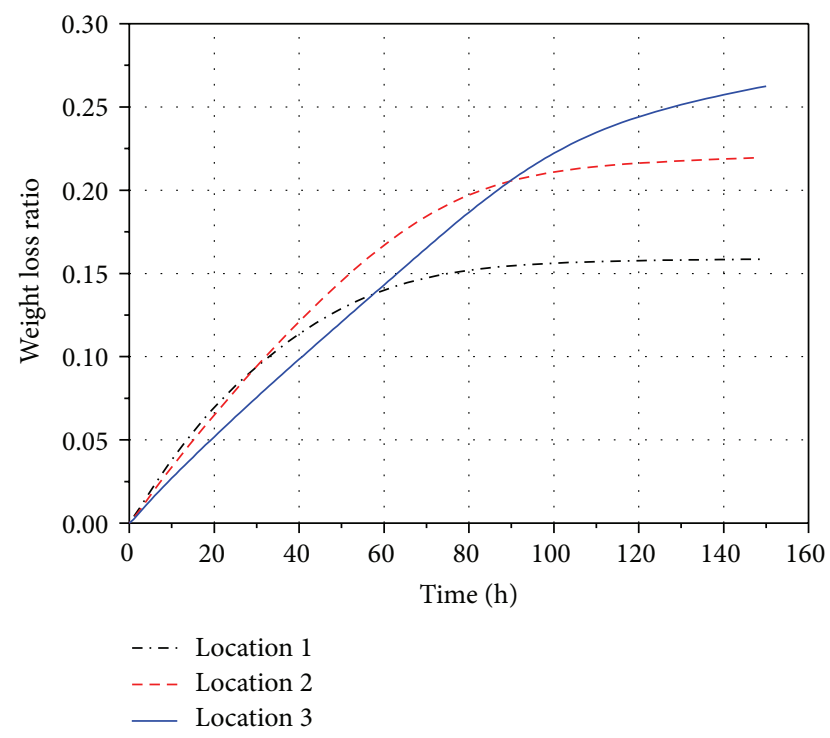

Figure 9: The weight loss ratio of locations 1, 2, and 3.

(1) In the bottom part of the reactor core, the matrix graphite of the spherical fuel elements is mainly oxidized by oxygen, while, in the middle part of the reactor core, the matrix graphite is mainly oxidized by carbon dioxide. Because of low temperature and low concentration of oxygen, in the upper part of the reactor core, the amount of the matrix graphite oxidation is very small.

(2) The fuel particles will be exposed if the outer $5 \mathrm{~mm}$ fuel-free zone of matrix graphite is all consumed by oxidation reactions. In the reactor core, at about $120 \mathrm{~h}$ the maximum local oxidation of matrix graphite will firstly reach $3.75 * 10^{4} \mathrm{~mol} / \mathrm{m}^{3}$ which means the outer fuel-free zone of matrix graphite is completely oxidized. 120 hours is a relatively long time and it is enough to take some protective measures. In addition, considering the heterogeneous oxidation on the surface of the matrix graphite and assuming the most severe condition, the first fuel particle will be exposed at about $5 \mathrm{~h}$. Even in this case, the SiC layer of the fuel particle still can retain the radioactive products.

(3) The bottom reflectors are mainly oxidized by oxygen and the maximum graphite oxidation is almost in IPDR. The maximum local weight loss ratio of the bottom reflectors is 0.26 at $150 \mathrm{~h}$, which happens in location 3 . This weight loss ratio would not result in fracture of the graphite of bottom reflectors. Furthermore, the graphite temperature of bottom reflectors would be reduced finally due to the inherent safety features of the HTR-PM and the oxidation reaction would not go on under the low temperature.

All of these oxidation results are concluded under the conservative assumption that the amount of air that could diffuse into the reactor is infinite. In the actual situations, the amount of air in the reactor cavity that could diffuse into the reactor core is limited. Thus both the amount of the matrix graphite oxidation in the reactor core and the amount of the nuclear grade graphite oxidation in the bottom reflectors will be much smaller. In addition, in the actual situations, some protective measures can be taken when the air ingress accident happens, which will be able to further mitigate the consequences of the accident.

The conclusions about the nuclear grade graphite oxidation in this paper are achieved from the preliminary analyses. Some further researches such as the effect of GITO on the graphite oxidation rate in BLDR will be carried out in the near future.

\section{Competing Interests}

The authors declare that they have no competing interests.

\section{Acknowledgments}

This work has been supported by the National Science and Technology Project (Grant no. ZX069).

\section{References}

[1] Y. Zheng, L. Shi, and Y. Dong, "Thermohydraulic transient studies of the Chinese 200 MWe HTR-PM for loss of forced cooling accidents," Annals of Nuclear Energy, vol. 36, no. 6, pp. 742-751, 2009.

[2] G. H. Lohnert and H. Reutler, "The modular HTR- a new design of high-temperature pebble-bed reactor," Nuclear Energy, vol. 22, no. 3, pp. 197-201, 1982.

[3] Y.-H. Zheng and L. Shi, "Air ingress analysis for two primary loop pipes rupture of HTR-PM," Atomic Energy Science and Technology, vol. 44, no. 1, pp. 253-257, 2010.

[4] B. Liu, Study on air ingress accident of $10 \mathrm{MW}$ high temperature gas-cooled test reactor [Ph.D. thesis], Tsinghua University, 1998.

[5] X. Zhou, Z. Yi, Z. Lu et al., "Graphite materials in pebble-bed high temperature gas-cooled reactors," Carbon Techniques, vol. 31, no. 6, pp. 9-13, 2012.

[6] H.-K. Hinssen, K. Kühn, R. Moormann, B. Schlögl, M. Fechter, and M. Mitchell, "Oxidation experiments and theoretical examinations on graphite materials relevant for the PBMR," Nuclear Engineering and Design, vol. 238, no. 11, pp. 3018-3025, 2008.

[7] S. S. Penner and M. B. Richards, "Oxidation of nuclear-reactorgrade graphite,” Energy, vol. 13, no. 6, pp. 461-468, 1988.

[8] A. Lauer, "The reactor dynamics program TINTE: code structure," Tech. Rep. PreJuSER-35313, Institut für Sicherheitsforschung und Reaktortechnik (ISR), 2003.

[9] H. Gerwin, W. Scherer, and E. Teuchert, “TINTE modular code system for computational simulation of transient processes in the primary circuit of a pebble-bed high-temperature gascooled reactor," Nuclear Science and Engineering, vol. 103, no. 3, pp. 302-312, 1989.

[10] A. Lauer and W. Scherer, "The reactor dynamics program TINTE: introduction and overview," Institut für Sicherheitsforschung und Reaktortechnik (ISR) PreJuSER-35324, 2003.

[11] B. Lee, H. Gerwin, H. F. Nießen et al., "On the validation of the reactor-dynamics code-system TINTE-post-calculations of the SANA-1 experiments with a radial reflector," Tech. Rep. 
KFA-ISR-IB 2/95, Institut für Sicherheitsforschung und Reaktortechnik (ISR), 1995.

[12] H. Gerwin and W. Scherer, "Zur Validierung des Reaktordynamik-programmsystems TINTE: Graphit-Korrosion mit Luft, Vergleichsrechnungen zum Experiment VELUNA," Tech. Rep. KFA-ISR-IB-8/92, Institut für Sicherheitsforschung und Reaktortechnik (ISR), 1992.

[13] Y. Zheng and M. M. Stempniewicz, "Investigation of NACOK air ingress experiment using different system analysis codes," Nuclear Engineering and Design, vol. 251, pp. 423-432, 2012.

[14] R. Moormann and H. K. Hissen, "Advanced graphite oxidation models. Basic studies in the field of high-temperature engineering," in Proceedings of the 2nd Information Exchange Meeting, Paris, France, October 2001.

[15] C. H. Oh, E. S. Kim, H. C. No et al., "Final report on experimental validation of stratified flow phenomena, graphite oxidation, and mitigation strategies of air ingress accidents," Tech. Rep. INL/EXT-10-20759, Idaho National Laboratory (INL), 2011.

[16] M. Ishihara, J. Sumita, T. Shibata, T. Iyoku, and T. Oku, "Principle design and data of graphite components," Nuclear Engineering and Design, vol. 233, no. 1-3, pp. 251-260, 2004.

[17] M. Eto and F. B. Growcock, "Effect of oxidizing environment on the strength of H451, PGX and IG-11 graphites," Carbon, vol. 21, no. 2, pp. 135-147, 1983.

[18] W. Xu, L. Shi, Y. H. Zheng et al., "Research on oxidation model of nuclear grade graphite IG-110," Atomic Energy Science and Technology, vol. 49, pp. 475-480, 2015. 

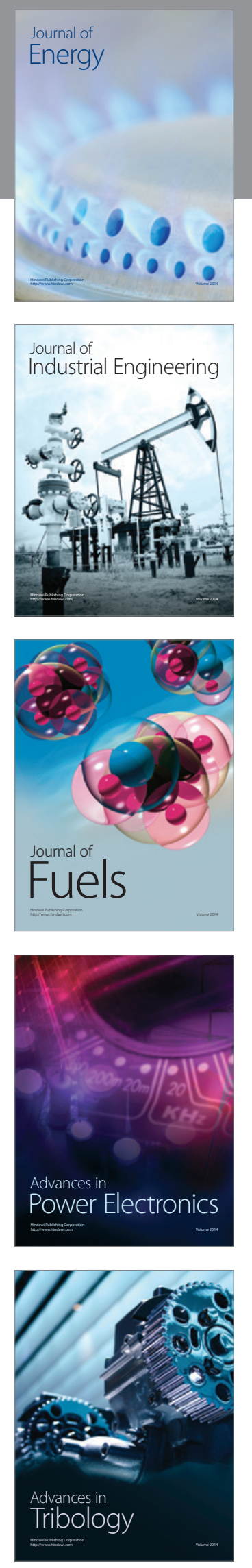
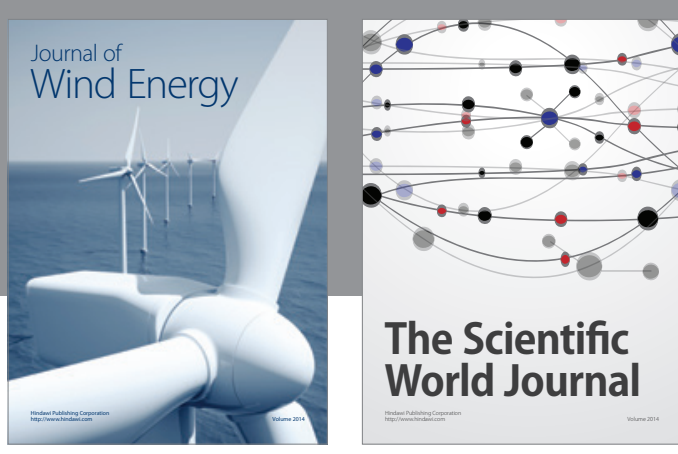

The Scientific World Journal
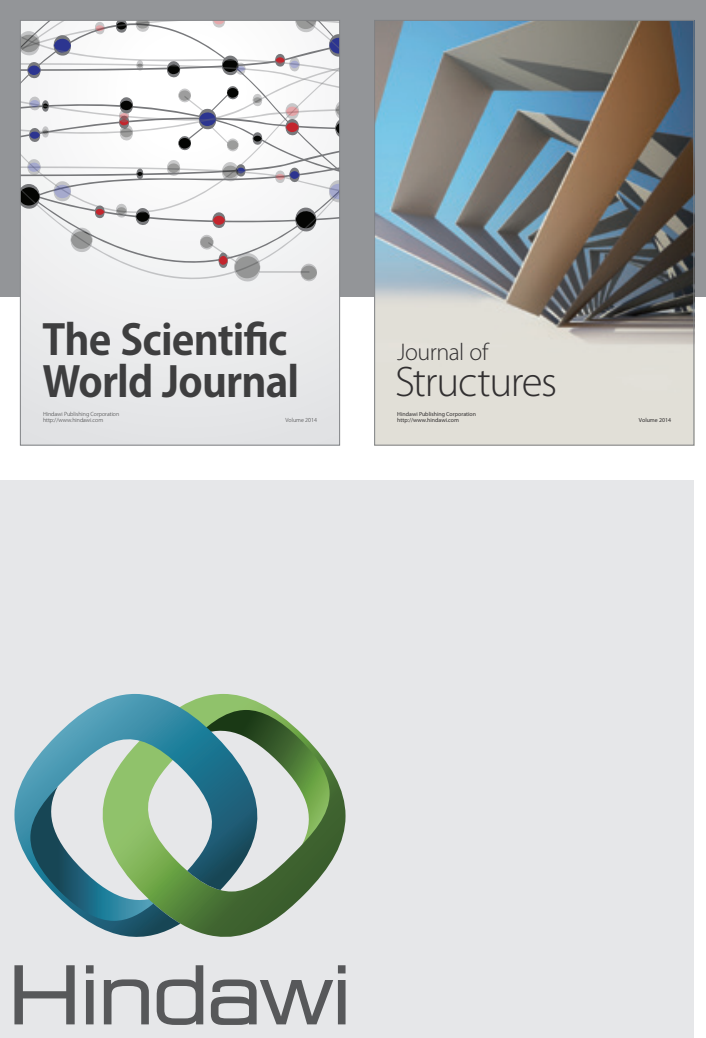

Submit your manuscripts at

http://www.hindawi.com
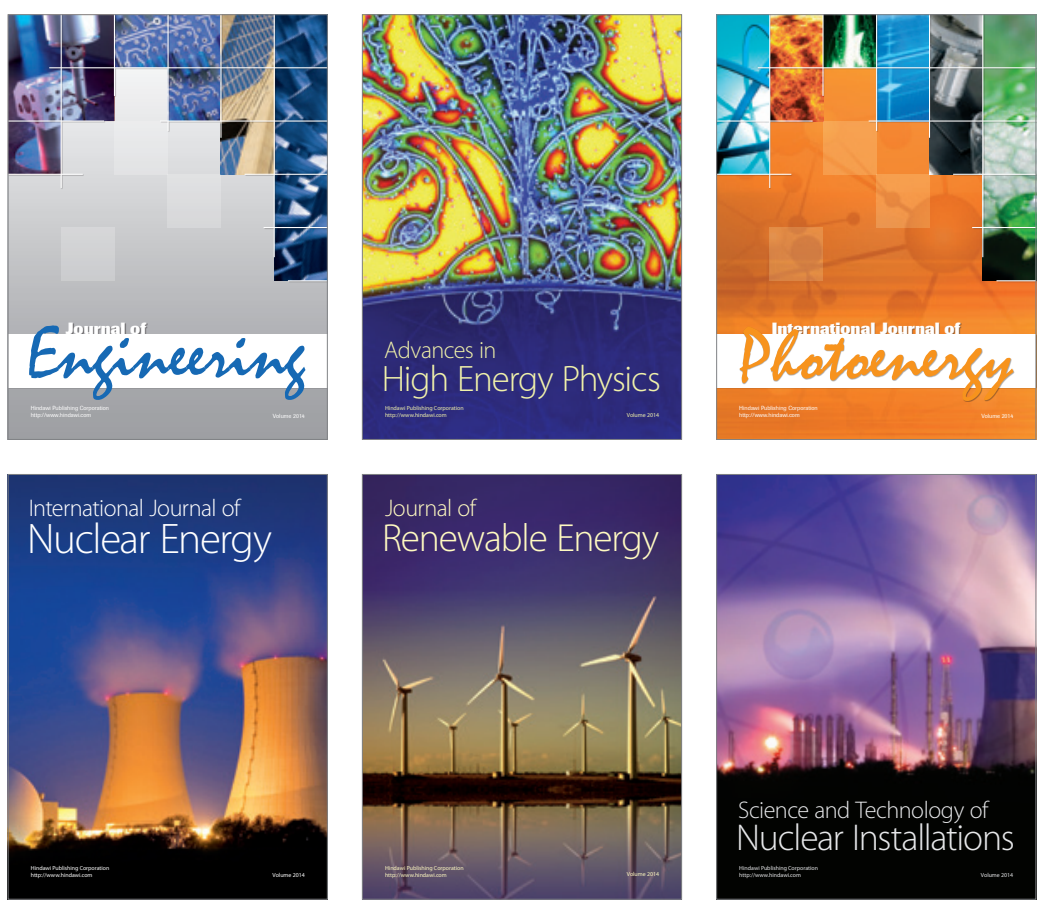
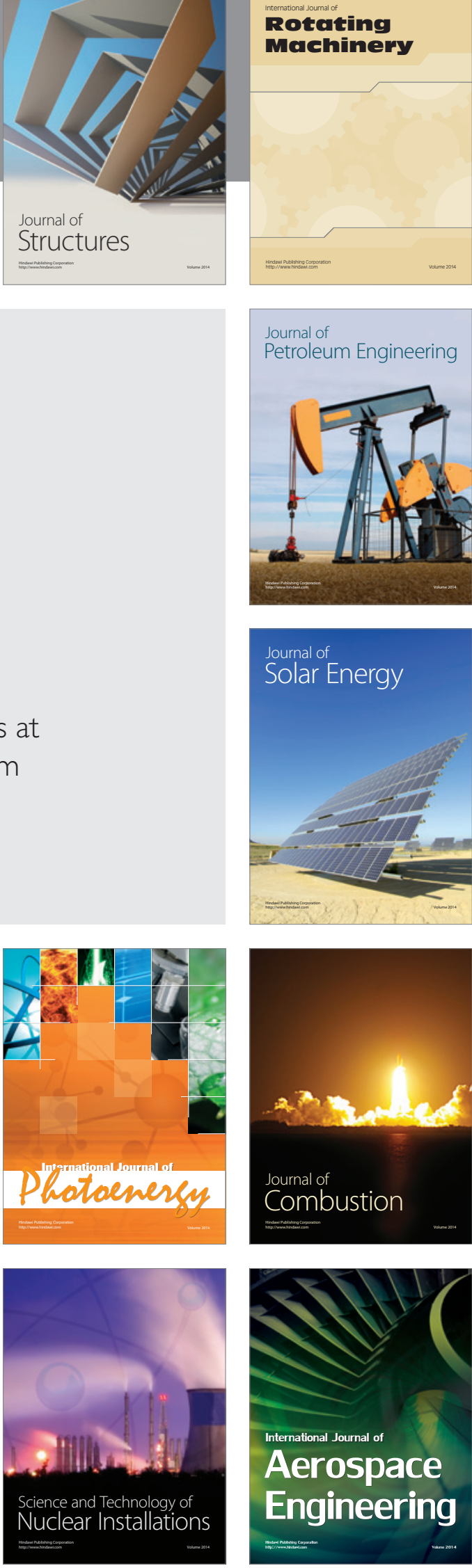